\title{
Effect of Life Skills Training on Social Skills of Hearing Impaired Students
}

\author{
${ }^{1}$ G. Movallali ${ }^{2}$ M. Ashori, ${ }^{3}$ S. S.Jalil-Abkenar' ${ }^{4}$ Z. Salehy \\ ${ }^{I}$ Pediatric Neurorehabilitation Research Center, University of Social Welfare and Rehabilitation Sciences, Iran, \\ ${ }^{2}$ Department of Psychology and Education of Exceptional Children, University of Tehran, Iran \\ ${ }^{3}$ Department of Psychology and Education, University of Social Welfare \& Rehabilitation Sciences, Iran \\ ${ }^{4}$ Department of Guidance and Counseling, National University of Malaysia
}

\begin{abstract}
Life skill training is extremely relevant to the social skillsof children. The purpose of the present research is to investigate the effectiveness of life skills training on the social skills of hearing impaired students between 10 and 12 years old.This research employed the experimental method using pretest and posttest design, with a control group. The participants were 38 male hearing-impaired students, with sensory-neural hearing in the range of 50 to 90 decibels. They were selected from two schools for the deaf in Tehran Province using a cluster sampling method. Subjects were randomly divided into an experimental group and a control group, each consisting of 19 students. The experimental group was subjected life skills training for 9 sessions, whereas the control group was not. The Wechsler intelligence test was used for matching the groups in their IQs, while their social skills rating scale was used for measuring their social skills. The data were recorded and statistically analyzed using MANOVA. The results of MANOVA showed that life skills training had a significant effect on the social skills and subscales (cooperation, assertiveness and self-control) in the experimental group, while in the control group no change was observed $(p<0.0001)$. Life skills training can improve the social skills of hearing impaired students. Therefore, training of life skills has a crucial role in improving the social skills of hearing impaired students, and deserves to be given more attention. Keywords:Life skills, social skills, hearing impaired students.
\end{abstract}

\section{Introduction}

Deafness is a heterogeneous situation with far-reaching effects on emotional, social, and cognitive development [1]. Hearing loss affects $15 \%$ to $26 \%$ of the world's population, with the highest prevalence in low income countries [2-4]. This review emphasizes on individuals with severe to profound deafness, with onset before language has been well-known. Roughly, 7 per 10.000 people in the overall population are in this group $[5,6]$. Auditory sense is one of the most vital sensory abilities of people, without which they lose most of their abilities to adopt with the environment around them. For ordinary people like us with the advantage of having an auditory sense, we have the opportunity of stating our desires and intentions with words and sentences any time we want. Undoubtedly, it is not possible to clarify the role of auditory sense in life. Sometimes, it is observed that some of the hearing impaired persons want more and expect to be provided more with the things they expect or wish to have. One of the main reasons for this social defect returns to the way they have been brought up during their childhood. Sometimes, parents of these children did not make it clear to them of their rights and due to their physical defect, the parents provided them whatever they wanted. Sometimes, they even violated the rights of other children for the advantage of their hearing impaired child, and in this way they have led their child to keep on expecting more, and to keep on asking for all that they needed. As a result, in their adulthood, these children often continues to expect too much of their own rights and to ask for more rights than they rightfully deserve. This problem causes the hearing impaired children to be rejected by others, and this makes these children face various problems in their life. Lack of social stimuli, especially for the children grown up in day and night schools or dormitories, leads them to be more isolated [7].

Social skills can be defined as behaviors that allow a child to interact with others successfully [8]. Howlin [9] suggests that social behavior is "the ability to relate to others in a mutually reinforcing and in a reciprocal fashion, and to adjust their social skills to the varying demands of interpersonal perspectives" [9]. Social skills are actions that help people interact with others. In school, the interactions may be with teachers, classmates, and other school staff. Later in life, the interactions may be with supervisors, co-workers, friends, and others. Adolescents and children with disabilities sometimes have behaviors that are unacceptable or awkward in social interactions. The lack of suitable social behaviors may be a characteristic of their disability. Students may lack a specific social behavior, they may show an inappropriate social behavior in a certain situation, or they may not be aware that a particular condition calls for a specific behavior [10]. The curriculum for students with disabilities can be separated into the areas, namely academic and nonacademic. Social skills training would be considered nonacademic. Conventionally, the emphasis on social skills has been 
overshadowed by academic skills. However, numerous instructors acknowledge the need for an increased emphasis on social skills improvement to promote greater social capabilities for students with high incidence disabilities [11]. Similar to other skills, social skills training must be deliberate, learned and practiced within the numerous natural settings and the environments that they would happen [12].

By providing instruction in social skills, hearing impaired students can learn to adjust various social situations and get along with others. Being weak in social skills can seriously limit an individual's opportunities in living arrangements, work situations, and leisure activities [10]. Social competency must focus on independence, self-confidence, socially acceptable behavior, and maintenance of friendships for the hearing impaired students who participate in the study. Primary competencies included in instruction should be achieving self-awareness, acquiring self-confidence, achieving socially responsible behavior, maintaining good interpersonal skills, achieving independence, achieving problem-solving skills, and communicating with others. Social skill training is typically an integral aspect of programs for hearing impaired people. It is essential that students maintain positive social relationships with their peers, family, teachers, and people within their community. "Social skills are often defined as a set of skills that include problem-solving, communication, decision-making, peer and group interactions, assertion and self-management" [11]. Social skills are observable and measurable behaviors that promote independence, acceptability, and a good quality of life. "These skills are crucial to adjustments and normal functioning, and deficits have been closely linked to psychopathology and behavior problems" [13]. Studies on people with impaired hearing have indicated that social skills are of utmost importance in the quality of life and adjustment of hearing impaired people into their community and vocation. Numerous studies have proven that the lack of appropriate social skills is a major factor contributing to the failure of hearing impaired persons in community placements [14]. In addition, Albert Bandura's Social Leaning theory can be applied for developing the social skills of students with disabilities. Social learning emphasizes the importance of the observation and subsequent modeling of behaviors, attitudes, and emotional reactions of others. This theory is based on the premise that social interactions play a fundamental role in the development of cognition. "Bandura's social cognitive theory suggests that behavior modification is a function of setting goals based on outcome expectations related with the behavior modification, the tasks asked to achieve those goals, and self-efficacy expectations for reaching the goals" [15].

World Health Organization (WHO) in 1997 reported that life skills are abilities which support students' overall development and reinforce their ability to encounter problems in life. The elementary skills for independent living should be meal preparation, personal hygiene, and job preparedness training [16]. The major goal should be to find out what needed to be taught, by moving them toward independence in adulthood. Goals should be developed in the areas of recreational, academic, prevocational and vocational, emotional and social skills. The key is to strike a balance between students being left in academic classes and functional life skills [17]. Life skills training procedure can teach young students how to make decision, how to use daring behavior, and how to think critically. To achieve the wanted results, all skills must be learned by the students [18].

Botvin [19-21] have settled a life skills training curriculum for avoiding substance abuse for junior or middle high school students. Life skills training programs have dramatic and immediate positive effects on adults, youth, and children in some countries [19-21]. Life skills program suggests that there are some abilities which help adolescents or children for the promotion of well-being and health and it is at the heart of skillsbased initiatives. Life skills that have been given attention in education for both secondary and primary levels are interpersonal relationship skills, effective communication, self-awareness, decision making, empathy, problem solving, critical thinking and creative thinking, coping with stress, and coping with emotions [22-24]. Lou, Wang, Tu and Gao [25] assumes that capability of young persons can be increased by these skills so that they can take responsibility for resisting negative pressures, make healthier choices, and avoid risky behaviors [25]. Therefore, life skills are a fundamental issue and need to be taught at all ages and all levels of students. Integrating life skills in educational training can potentially help individual to modify their approach in life and promote healthy life [27].

Several attempts have been made to training of life skills. For instance, life skills project have led to the Armenian education system adopting it as a component of a general effort in their education reform [27]. In another study, life skills was intended to encourage pupils' all round progress in Iceland Ministry of Education, Science and Culture, to enable them to better contract with the demands and challenges of everyday life [28]. In yet another study in 2006, Ministry of Education and Training in Vietnam led life skills education that talked about individual's ability (attitude, values, knowledge, and skills) to do life functions and fully participate in daily life [29]. To measure life skills in adolescents, Sharma [30] used a survey to analyze the level of life skills in adolescents of a secondary school at Katmandu. Based on WHO's definition, Sharma organized a questionnaire in English with several questions to examine life skills. According to the findings, $51 \%$ of adolescents had higher level of life skills. In addition, another result related to life skills awareness of teachers is that in their knowing, life skills are equal with vocational training and livelihood skills [30]. 
Most children learn social skills from their interactions with other children, family members, friends, and adults. However, hearing impaired children will need to learn social skills more directly. This may include the use of individualized methods and the use of a specific curriculum. Nevertheless, further study is needed to confirm existing findings and to extend the knowledge base, particularly with regard to improving social skills for hearing impaired children. The purpose of this study is to calculate the effectiveness of life skills training on the social skills of hearing impaired students.

\section{Material and Methods}

This study was approved by Ethics Committee of University of Social Welfare and Rehabilitation Sciences. An experimental pretest, posttest with control group design was used. Participants included 38male hearing impaired studentswith sensory-neural hearing in the range of 50 to 90 decibels andbetween 10 and 12years of age who enrolled in the deaf schools in Tehran (academic year 2012-2013).Participants were selected by cluster sampling technique. From the list of schools, two schools selected randomly. Participants were divided into two groups by randomly (experimental and control group), each of which was consisted of 19 students.Experimental group received life skill training in 9 sessions (two 60-min sessions a week), while control group did not. No contact between members of the research team and sample subjects occurred in this period. The teacher completed the Social Skills Rating Scale or SSRS (Teacher Form) for the subjects at pretest and posttest.Outcome measures at pretest andposttest obtained ofSSRS for subjects into each group.

\subsection{Social Skills Rating Scale (SSRS)}

This scale was developed by Frank Gresham and Stephen Elliot in 1990. This 30-item measure consists of three subscales with 10 items each. The subscale "cooperation" assesses behaviors such ashelping others, sharing materials, and complying with rules and directions. The second subscale, "Assertion", assesses initiating behaviors such as asking others for information, introducing oneself and responding to the actions of others. The third subscale, "self-control", measures behaviors that emerge in conflictsituations, such as responding appropriately to teasing, and in non-conflict situations that require taking turns and compromising [31].A total social skills scale score is computed, with a range of 0-60. SSRS-T are rated on a 3-point Likert scale ranging from 0 (never) to 2 (often). Higher scores indicate better social skills and lower scores indicate social skills impairment. The internal consistencies for the SSRS seem satisfactory. The internal consistency of the SSRS subscales ranged from .51 to .91, with a mean internal consistency of .75 [32]. Shahim [33] has found high alpha coefficients (.92) for the teacher versions. Studies examining convergent validity have found moderate to high correlations between the SSRS and other social competence measures, including the Woodcock-Johnson Scales of Independent Behavior [34], the Vineland Adaptive Behavior Scales [35] and the Behavior Assessment System for Children [36]. Flanagan [36] found a high positive correlation $(r=.58)$ between parent ratings on the BASC and the SSRS. However, teacher ratings showed a low correlation between the BASC and the SSRS $(r=.23)$.

\subsection{Intervention Program of Life Skill}

This training program provided by World Health Organization[37]. According to Table 1 this program includes a catalogue of skills.

Table 1.Description of Items in the Life Skill Program

\begin{tabular}{|c|c|c|}
\hline Skills & Sessions & Context of program in each session \\
\hline- & 1 & Familiarization with life skill program and goals \\
\hline $\begin{array}{l}\text { Self- } \\
\text { development }\end{array}$ & 2 & $\begin{array}{l}\text { Identify positive characteristics of students, diagnosis between misunderstanding and make } \\
\text { a mistake } \\
\text { Identify desirable or not characteristics, development and change perception in the span life }\end{array}$ \\
\hline $\begin{array}{l}\text { Emotions- } \\
\text { development }\end{array}$ & 4 & $\begin{array}{l}\text { Rejected perception and loneliness on others, effective methods of coping with rejection and } \\
\text { loneliness, role of self in sensation assertion } \\
\text { Identify unfavorable emotions, effective methods of adjustment with emotions, tolerance of } \\
\text { rejection and loneliness }\end{array}$ \\
\hline $\begin{array}{l}\text { Social- } \\
\text { development }\end{array}$ & $\begin{array}{l}6 \\
7\end{array}$ & $\begin{array}{l}\text { Cooperation and collaboration, effective interpersonal interactions, decision-making } \\
\text { Effective skills inconflict management, identify rejection and loneliness causes, external } \\
\text { word thinking of other perspective }\end{array}$ \\
\hline $\begin{array}{l}\text { Cognitive- } \\
\text { development }\end{array}$ & 8 & $\begin{array}{l}\text { Selections and diagnosis of important, separation of reasonable belief, attention to positive } \\
\text { and negative outcome indecisions } \\
\text { Coping with stress and emotions, review of programs }\end{array}$ \\
\hline
\end{tabular}




\section{Results}

In experimental and control group average ages were 10.02 years and 12.31 and average IQ were 95.17 and 97.68. The first research question was to investigate the effectiveness of life skills training on social skills inhearing impaired students. In order to compare the social skills for the groups (experimental and control) at the pretest and posttest, analyses were conducted using Analysis of Covariance (ANCOVA).Program (life skill training) impact was first determined contrasting pretest with posttest scores ofSSRS in both control and experimental groups by ANCOVA (Table 2). The Analysis of Covariance (ANCOVA) statistical procedure examined the inequalities between the group means while taking into account the influence of a Covariate. By comparing the means for the two groups (experimental and control), the linear association between the pretest and posttest were given, $\mathrm{F}_{(1,35)}=.613, \mathrm{P}=.078$. Furthermore, for this analysis, was confirmed the equalityofVariances assumption.

Table 2. Analysis of Covariance Summary

\begin{tabular}{rrrrrrr}
\hline Source & SS & Df & MS & F & Sig & $\mathbf{\eta}^{2}$ \\
& & & & & & .396 \\
Pretest & 77.311 & 1 & 77.311 & 28.143 & $<.0001$ & .743 \\
Group & 1099.074 & 1 & 1099.074 & 400.099 & $<.0001$ & \\
Error & 69.156 & 35 & 2.747 & & & \\
& 12927.708 & 37 & & & & \\
\hline
\end{tabular}

The effect of the covariate (pretest) was significant, $\mathrm{F}_{(1,35)}=28.143$, $\mathrm{p}<.0001$ (Table 2), indicating that the pretest and posttest were significantly correlated. Also, the effect of between groups was significant, $\mathrm{F}_{(1,35)}=$ 400.099, $\mathrm{p}<.0001$. In summary, the ANCOVA results show that two groups' means were significant difference that's means, life skill training has a positive and significanteffect.

In order to compare the subscales social skills (cooperation, assertion and self-control) for the experimental and control groups at the pretest and posttest, analyses were conducted using Multivariate Analysis of Covariance (MANCOVA). The descriptive statistics were compared with respect to each group's scores on the social skills subscales (cooperation, assertion \&self-control). Mean scores and Standard Deviation for each group were used as an overall group index(Table 3).

Table 3.Descriptive Statistics for each Subscale and Group (pretest \& posttest)

\begin{tabular}{rrrrr}
\hline Subscales & Situation & Experimental group & Control group \\
\hline \multirow{3}{*}{ Cooperation } & & Mean & SD & Mean \\
& Pretest & 10.36 & 1.02 & 10.11 \\
Assertion & Posttest & 14.09 & 1.75 & 1.31 \\
& Pretest & 8.08 & 0.98 & 7.92 \\
Self-control & Posttest & 12.76 & 1.07 & 8.03 \\
& Pretest & 7.85 & .94 & 7.81 \\
& Posttest & 10.79 & 1.11 & 7.96 \\
\hline
\end{tabular}

To assess the Social Skills Rating Subscale to discriminate between deaf students we conducted MANCOVA. Total score on the cooperation, assertion and self-control were used as predictor variables. The overall Wilk's lambda was significant, $\mathrm{F}_{(3,31)}=2.106, \mathrm{p}=.0001$, indicating that overall predictors differentiated between the two groups. In order to understanding differences among subscales scores of cooperation, assertion and self-control skills between experimental and control groups, were used MANCOVA (Table 4).

Table 4. Multivariate Analysis of Covariance Summary

\begin{tabular}{crrrrrrrr}
\hline Source & Depended variable & SS & Df & MS & F & Sig & $\boldsymbol{\eta}^{2}$ \\
\hline Pretest & Cooperation & 28.074 & 1 & 289.074 & 590.163 & $<.0001$ & .309 \\
& Assertion & 37.256 & 1 & 37.256 & 74.866 & $<.0001$ & .407 \\
& Self-control & 19.517 & 1 & 19.517 & 39.085 & $<.0001$ & .310 \\
Group & Cooperation & 189.122 & 1 & 189.122 & 478.550 & $<.0001$ & .847 \\
& Assertion & 109.643 & 1 & 109.643 & 278.081 & $<.0001$ & .901 \\
& Self-control & 66.098 & 1 & 66.098 & 168.111 & $<.0001$ & .843 \\
\hline
\end{tabular}

According to Table 4, there are significant difference among subscales scores of cooperation, assertion and self-control skills between experimental and control group $(\mathrm{p}<.0001)$. The results of MANCOVA showed that (Table 4) life skills training had significant and positive effect on the cooperation $(\mathrm{F}=478.50, \mathrm{p}<.0001)$, assertion $(\mathrm{F}=278.081, \mathrm{p}<.0001)$ andself-control skills $(\mathrm{F}=168.111, \mathrm{p}<.0001)$. 


\section{Discussion}

First, this study evaluated the effectiveness of life skills training on the social skills of hearing impaired students into two groups (experimental and control) at the pretest and posttest. Second, differences between experimental and control group were examined using subscales of social skills (cooperation, assertion, and selfcontrol) at the pretest and posttest.

With respect to the first research question, the present study supports the effectiveness of life skills training on the social skills of hearing impaired students. This result is similar to Turner, Mc Donald and Somerset[38], which concluded that there is a significant relationship among life skills, mathematical reasoning, and critical thinking. Furthermore, the result is similar to that of the study by Korinek and Popp [39], which concluded that verbal and nonverbal behaviors affect peer interactions and social consequences.Current studies within the field of special education that relate to this study center are looking at students participation and progress within the general education curriculum [40]. Many educators are seeking to determine if the standards-based reform is creating a curriculum for hearing impaired students that is focusing more on academic skills, resulting in less time being spent on functional skills [7].

This result can be explained by concluding that although some hearing impaired students are able to pick up positive skills through their everyday communications with peers and adults, it is important that teachers and parents reinforce learning of social skills with direct and indirect life skills training. From the result of this increase in scores within the experimental group, it can be assumed that over time, a life skills training curriculum can have positive effects. Consequently, a functional curriculum supported by academic training will enable hearing impaired students to utilize functional skills to live and work within their community. Therefore, the curriculum utilized in the education of hearing impaired students must include integrated life skills as well as an academic curriculum. This means that it is vital for hearing impaired students to be exposed to essential life skills such as personal or social skills.

For the second research question, the results of the present research show that a life skills training has a significant and positive effect on cooperation, assertion, and self-control skills. This finding is similar to that of the study by Mahvashevernosfaderani, Adibsereshki, and Movallali[41], which concluded that life skills training has significant effect on the cooperation, assertion, and self-control skills in the hearing loss students. Furthermore, these results are similar to that of the study by Kazemi, Momeni, and Kiamarsi [37], which concluded that training of life skills increases behavioral skills of students with dyscalculia.

This result can be explained by concluding that hearing impaired students lack social skills. However, the major content areas in their training curriculum are being pushed in legislation rather than being focused in the functional curriculum for hearing impaired students. This study has addressed the issue of whether or not a life skill instruction curriculum positively affects the performance of hearing impaired students on knowledgebased assessment and a social skill rating scale [42].On the other hand, for hearing impaired students, a functional curriculum supported by an academic curriculum would enable them to utilize functional skills to live and work within their community. However, the current trend is that students are exposed to the general education curriculum that prevents students from receiving essential instructions in nonacademic areas such as social skills. The increase in scores of the social skills curriculum indicates that long-term extensive instruction could be beneficial to be continued with the incorporation of necessary functional life skills into the curriculum for the hearing impaired students.In addition, a curriculum that addresses academic skills and life skills could be utilized to address other vital issues within the field of special education. Current trends in special education reflect several issues, namely integration, participation in an outcomes-based assessment process, selfdetermination, functional life skills, and transitional services [43]. Finally, the mandate for transitional services has spurred a new movement. These services included postsecondary education, vocational training, integrated employment, continuing and adult education, adult services, independent living, and community participation. The life skill instruction helps students to "learn and develop the critical skills they will need to be productive and successful upon making the transition from school to community life and work" [44].

Several limitations of the current research should be noted. First, the nature of working with hearing impaired students is often inconsistent. It is often difficult to determine progress of hearing impaired students because they progress in slower rates and require additional time and instruction to understand essential concepts. Special education research, because of its involvedness, may be hardest to do, compare with research in other sciences. The feature of special education research that makes it more complex is the variability of the participants [45]. Furthermore, the demographics represented are limited with regard to race and ethnicity. This limitation makes it difficult to generalize the findings of the study to the general population. Furthermore, the small sample size could be viewed as a potential limitation. This study involved only 38 student participants. Thus, it would be difficult to relate the findings to the overall population of special education students. Along the same lines as the limitations that the population might impose, the time constraints in conducting the study could also be a factor affecting the outcomes. 
Nevertheless, recommendations for further research that emanate from this study have created numerous opportunities for further research. First, this study could be expanded to include a larger population of student participants. Furthermore, the life skill program contains three additional domains, which focus on cooperation, assertion, and self-control skills. This would provide opportunities for researchers to demonstrate that improvements in these specific areas can be made following the implementation of the curriculum. Furthermore, it would be beneficial to conduct a longitudinal study to determine the degree of students' improvements over the course of their middle and high school life, as the instruction is provided throughout their education. Finally, additional studies resulting from this research could revolve around incorporating several portions of the life skills syllabus into various populations such as students with emotional disabilities or learning disabilities.

\section{References}

[1]. Fellinger, J.,Holzinger, D.,Sattel, H.,Laucht, M., Goldberg, D. Correlates of mental health disorders among children with hearing impairments.Journal ofDevelopment Medical Children Neural.2009; 5: 635-41.

[2]. Agrawal, Y., Platz, E.A., Niparko, J.K. Prevalence of hearing loss and differences by demographic characteristics among US adults: data from the National Health and Nutrition Examination Survey.Arch Intern Med. 2008; 168: 1522-30.

[3]. Beria J.U., Raymann, B.C., Gigante, L.P. Hearing impairment and socioeconomic factors: a population-based survey of an urban locality in southern Brazil. Review Panama Salud Publication. 2007; 21:381-87.

[4]. WHO.Deafness and hearing impairment. April, 2010. http://www. Who.Int/ media Centre/ factsheets/fs300/en/index.html (accessed April 26, 2011).

[5]. Bubbico, L., Rosano, A., Spagnolo, A. Prevalence of pre-lingual deafness in Italy. Act Otorhinolaryngology Ital. $2007 ; 27: 17-21$.

[6]. Mitchell, R.E. How many deaf people are there in the United States? Estimates from the Survey of Income and Program Participation.J Deaf Stud Deaf Edu.2006; 11: 112-19.

[7]. Haghighatzade, R. A. comparison of the emotional intelligence in two groups of deaf and non- deaf students in Isfahan. Journal of Basic and Applied Scientific Research. 2012; 2(9): 9573-76.

[8]. Gresham, F., Elliot, S. Assessment and classification of children's social skills: A review of methods and issues. Journal of School Psychology Review.1984; 13: 292-301.

[9]. Howlin, P. An overview of social behavior in autism. In E. Schopler\& G.B. Mesibov (Eds.), Social behavior in autism. New York: Plenum Press; 1986: 103-26.

[10]. Smith, L. Text for social skills. Retrieved January 31, 2005, from http://www.sarasota.usf.edu/SpecialEducation/social\%20skills.htm. 2001.

[11]. Kolb, S., Hanley-Maxwell, C. Critical social skills for adolescents with high incidence disabilities: parental perspectives. Journal of Council for Exceptional Children. 2003; 69(2):163-179.

[12]. Hallahan, D., Kauffman, J. Exceptional learners: introduction to special education. Boston: Allyn\& Bacon; 2000: 247-49.

[13]. Matson, J., Mayville, E., Lott, J., Bielecki, J., Logan, R. A comparison of social and adaptive functioning in persons with psychosis, autism, and severe or profound mental retardation.Journal of Developmental and Physical Disabilities.2003; $15: 11-18$.

[14]. Paraschiv, I., Olley, G. Generalization of social skills: Strategies and results of a training program in problem solving skills. U.S. Department of Education; 1999.

[15]. Heller, T., Rimmer, J. Exercise adherence among adults with mental retardation. RRTC on Aging with Developm ental Disabilities. 2006.

[16]. World Health Organization (WHO). Life Skills Education in Schools.Program on Mental Health.Division of mental health and prevention of substance abuse. World Health Organization. Geneva. 1997.

[17]. Sutton, J. Special education: A biblical approach South Carolina: Hidden Treasure. 1993.

[18]. Botvin, G.J., Griffin, K.W. Life skills training: empirical findings and future directions. Journal of Primary Prevention. 2004; 25(2): 211-32.

[19]. Botvin, G.J., Baker, E., Dusenbury, L., Tortu, S., Botvin, E.M. Preventing adolescent drug abuse through a multimodal cognitivebehavioral approach: Results of a three-year study. Journal of Consulting and Clinical Psychology.1990; 58: 437-446.

[20]. Botvin, G.J., Kantor, L.W. Preventing alcohol and tobacco use through Life Skills Training. Journal of Alcohol Research and Health.(2000); 24: 250-57.

[21]. Botvin, G.J., Griffin, K.W., Paul, E., Macaulay, A.P. Preventing tobacco and alcohol use among elementary school students through Life Skills Training. Journal of Child \& Adolescent Substance Abuse.2003; 12: 1-17.

[22]. World Health Organization (WHO). Partners in Life Skills education. Geneva: United Nations Inter-Agency Meeting. 1999.

[23]. Mangrulkar, L., Whitman, C.V., Posner, M. Life skills approach to child and adolescent healthy human development. Pan American Health Organization.Health and Human Development Programs (HHD), a division of Education Development Center, Inc. (EDC). 2001.

[24]. Kord-Noghabi, R.,PashSharifi, H. Preparation and compilation of a life skills curriculum for students in the high school period. Quarterly Journal of Educational Innovations.2008; 24: 47-56.

[25]. Lou,C., Wang, X., Tu X, Gao, E. Impact of life skills training to improve cognition on risk of sexual behavior and contraceptive use among vocational school students in shanghai, China. Journal of Reproduction \& Contraception.2008; 19(4): $239-251$.

[26]. Economic and Social Commission for Asia and the Pacific (ESCAP). Strengthening Life Skills for Positive Youth Health Behavior.An overview and discussion paper.United Nations; 2009.

[27]. Ministry of Education and Science of Armenia. Life skills project implementation in the Armenian education system. A project sponsored by UNICEF and the Ministry of education and science. Yerevan, Armenia. 2001.

[28]. Ministry of Education of Iceland. National curriculum guide for compulsory school.Life skills.Ministry of Education, Science and Culture.Iceland.2004.

[29]. Ministry of Education and Training in Vietnam. Life skills mapping in Vietnam.National Institute for education strategy and curriculum (Vietnam). Hanoi, UNESCO, 76 p., Bibl: 2006: 63-65.

[30]. Sharma, S. Measuring life skills of adolescents in a secondary school of Kathmandu: an Experience. Kathmandu University Medical Journal. 2003; 1(3): 170-176. 
[31]. Vander Oorda, S., Van der Meulenb, S.E.M., Prinsa, P.J.M., Oosterlaanc, J., Buitelaard, J.K., Emmelkampa, P.M.G. A psychometric evaluation of the social skills rating system in children with attention deficit hyperactivity disorder.Journal of Behavior Research and Therapy.2005; 43: 733-746.

[32]. Gresham, F.M., Elliot, S.N. Social skills rating system manual. Circle Pines, MN: American Guidance Service, 1990.

[33]. Shahim, S. Correlations between parents and teachers' ratings of social skills for a group of developmentally disabled children in Iran. Psychological Reports.1999; 85: 863-866.

[34]. Merrell, K.W., Popinga, M. R. The alliance of adaptive behavior and social competence: An examination of relationships between the scales of independent behavior and the social skills rating system. Research in Developmental Disabilities.1994; 1:39-47.

[35]. Albertus, C., Birkinbine, J., Lyon, M.A., Naibi, J. A validity study of the social skills rating system-teacher version with disabled and nondisabled preschool children.Journal of Perceptual and Motor Skills.1996; 83: 307-316.

[36]. Flanagan, D., Alfonso, V., Primavera, L., Povall, L., Higgins, D. Convergent validity of the BASC and SSRS: Implications for social skills assessment. Journal of Psychology in the Schools. 1996; 33: 13-23.

[37]. Kazemi, R., Momeni, S., Kiamarsi, A. The effectiveness of life skills training on the social competence of students with dyscalculia.Journal of Learning Disabilities. 2011; 1(1): 94-108.

[38]. Turner, N. E., Mc Donald, J., Somerset, M. Life skills, mathematical reasoning and critical thinking: A curriculum for the prevention of problem gambling. Journal of Gambling Studies.2008; 24(3): 169-181.

[39]. Korinek, L., Popp, A. Collaborative mainstream integration of social skills with academic instruction.Journal ofPreventing School Failure. 2004; 41(4): 148-160.

[40]. Hager, K., Slocum, T. Alternate assessment: No child left behind during statewide testing. Annual Conference Proceedings of the American Council on Rural Special Education; 2002.

[41]. Mahvashevernosfaderani, A., Adibsereshki, N., Movallali, G. The effectiveness of life skills training on the social skills of hearing impaired secondary school students in inclusive schools.Journal of Research on Rehabilitation Science. 2012; 8(3): $477-488$.

[42]. Shoemaker, M.E. Comparing social skills in children with autistic disorder and pervasive developmental disorder not otherwise specified. A Thesis submitted to the graduate faculty of the Louisiana state university and agricultural and mechanical college for the degree of Master of Arts in the department of psychology. 2009.

[43]. Brolin, D. Life centered career education. The Council for Exceptional Children; 1997: 146-47.

[44]. Ashoori, M., Jalil-abkenar, S.S., Ashoori, J., Abdollahzadeh Rafi, M., HasanzadehAvval, M. Learning disorders and academic skills. 1 st ed. Tehran.Roshdfarhang Publications; 2012: 23-24.

[45]. Odom, S., Brantlinger, E., Gersten, R., Horner, R., Thompson, B., Harris, K. Research in special education: Scientific methods and evidence-based practices. Council for Exceptional Children. 2005;71(2):137-148. 